\title{
In vivo evaluation of the impact of various border molding materials and techniques on the retention of complete maxillary dentures
}

\section{Ocena in vivo wpływu różnych materiałów i technik uszczelnienia brzeżnego na utrzymanie protez całkowitych w szczęce}

\author{
Tameem Khuder Jassim ${ }^{A-F}$, Ali Ehsan Kareem ${ }^{A-F}$, Mohamed Adnan Alloaibi ${ }^{A-F}$ \\ Department of Prosthodontics, College of Dentistry, Mustansiriyah University, Baghdad, Iraq \\ A - research concept and design; B - collection and/or assembly of data; $C$ - data analysis and interpretation; \\ $D$ - writing the article; $E$ - critical revision of the article; $F$ - final approval of the article
}

\section{Address for correspondence \\ Tameem Khuder Jassim \\ E-mail: drtameemkh@gmail.com \\ tamem.kh@uomustansiriyah.edu.iq}

Funding sources

None declared

Conflict of interest

None declared

Received on September 13, 2019

Reviewed on November 3, 2019

Accepted on December 5, 2019

Published online on June 30, 2020

Cite as

Jassim TK, Kareem AE, Alloaibi MA. In vivo evaluation of the impact of various border molding materials and techniques on the retention of complete maxillary dentures. Dent Med Probl. 2020;57(2):191-196. doi:10.17219/dmp/115104

DOI

$10.17219 / \mathrm{dmp} / 115104$

Copyright

(c) 2020 by Wroclaw Medical University

This is an article distributed under the terms of the

Creative Commons Attribution 3.0 Unported License (CC BY 3.0)

(https://creativecommons.org/licenses/by/3.0/).

\begin{abstract}
Background. Different techniques and impression materials are employed in the process of fabricating complete denture (CD) bases.

Objectives. The aim of this study was to determine differences in the denture base retention for acrylic maxillary CDs when using 2 different techniques and impression materials. Specifically, the green stick compound impression material was used for the sectional border molding technique and this was compared to using the addition vinyl silicone impression material with the single-step technique.

Material and methods. A crossover study was conducted on 10 participants who were completely edentulous in the upper arch ( 6 men and 4 women), aged $43-70$ years. The participants' trays were split into 2 treatment groups: the P-group; and the Z-group. Addition vinyl silicone was used for single-step border molding in the P-group, followed by light-body final-wash impression. For the Z-group, the green stick compound was used for sectional border molding, followed by a final wash using a zinc oxideeugenol material.To quantify the retention force of the denture base in kilograms-force, a digital force gauge was used.

Results. The measurements indicated significantly higher mean retention values $(p=0.000)$ in the P-group (4.02 $\pm 1.66 \mathrm{kgf}$ ) as compared to the Z-group (1.48 $\pm 0.90 \mathrm{kgf})$.

Conclusions. The results suggest the superiority of using the single-step border molding technique in the upper arch with the addition vinyl silicone material owing to the enhanced base retention of the acrylic denture base.
\end{abstract}

Key words: complete denture, dental impression technique, prosthesis retention

Słowa kluczowe: proteza całkowita, technika wycisku stomatologicznego, utrzymanie protezy 


\section{Introduction}

Dental disease is a condition that continues to heavily affect the older portion of the population; it is likely to cause such individuals to lose most of their natural teeth. ${ }^{1}$ This condition can lead to complete edentulism, brought about by the loss of the individual's entire set of original teeth along with the resorption of the alveolar bone. The impact of such a loss is immense - it influences chewing, phonation and other stomatognathic functions, at the same time resulting in adverse social consequences. Furthermore, from a clinical standpoint, one systematic review which assessed the association between oral function and dentition determined that the possession of less than 20 teeth, of which 9 or 10 pairs are in contact, is linked to a diminished masticatory ability and efficiency. ${ }^{2}$

One of the main aims of prosthetic dentistry is to improve the performance of removable prostheses in terms of their retention, stability and denture support. ${ }^{3}$ This can be achieved through the use of individual trays and impression materials of a higher accuracy, as recommended in various studies. ${ }^{4,5}$ Making impressions is one of the most significant stages of denture fabrication. Boucher laid out 5 primary objectives of complete denture (CD) impressions: retention; stability; support; esthetic value; and the preservation of the alveolar ridge. ${ }^{6}$ In CD prosthodontics, the accuracy of the final impression stage is of crucial importance in obtaining a CD. It involves an initial step of determining the vestibule with the use of the border molding technique, and then making the impression of the target edentulous arch. ${ }^{7}$

One can describe border molding as "the shaping of impression material along the border areas of an impression tray by functional or manual manipulation of the soft tissue adjacent to the borders to duplicate the contour and size of the vestibule". ${ }^{8[\mathrm{p} . e 17]}$ It can also be described as the means of establishing the prosthesis extension through manual or functional tissue control, leading to shaping the border region of the material used in an impression. ${ }^{8}$

When utilising a low-fusing impression compound, one study estimated that 17 insertions by several dentists would be needed to perform border molding in the same patient. ${ }^{9}$ Although the produced impressions were of high precision, the use of a low-fusing impression compound in border molding was time-consuming and laborious, particularly for new students. It is preferable that the chosen border molding material should be one that establishes contact with the whole vestibular sulcus area in its plastic state, and in a single insertion. ${ }^{9}$ A material that enables the synchronized molding of all borders provides the following benefits: fewer insertions of trays for border molding are needed; and the concurrent formation of all borders prevents faults in one section from impacting the contours in another section. ${ }^{10}$
When employing the sectional technique, the material of choice is a low-fusing impression compound. ${ }^{11}$ On the other hand, polyether with the addition of silicone of various viscosity is used in the single-step border molding technique. ${ }^{12,13}$ When evaluated using the OHIP-Edent (Oral Health Impact Profile for edentulous patients) scale, which assesses the quality of dentures and the masticatory ability, the use of the conventional technique (with a low-fusing material) for forming dental prostheses does not provide as satisfactory results in terms of clinical performance as the more streamlined technique (using silicone). Furthermore, the adjustment time is not any longer in the case of the streamlined technique; rather, the involved time and financial cost are decreased in comparison with the conventional technique. This makes the streamlined technique ideal for the formation of CDs. ${ }^{14}$ The streamlined technique involves the use of silicone in place of a low-fusing compound, and the advent of a silicone elastomer constitutes significant development in the formation of denture impressions. ${ }^{15}$ Silicone is not only easy to mold, but it also offers high levels of precision and dimensional stability. As a substitute for a low-fusing compound, heavy-body putty silicone is frequently selected for border molding, as it is both viscous and kneadable, has a homogenous texture, and is slow-setting. Thus, it allows the silicone to be kneaded along the entire border of a tray and to be formed in one attempt. ${ }^{13}$

The aim of this study was to compare the use of the green stick compound as a low-fusing material together with zinc oxide-eugenol impression paste with the use of addition silicone (polyvinyl siloxane) and light-body addition silicone to determine the retention of the acrylic complete upper denture base.

\section{Material and methods}

Ten completely edentulous participants were randomly selected for the study. All the participants had visited the clinic for prosthodontic restoration through new upper CDs. The exclusion criteria comprised a fibrous ridge, ridge resorption, tissue undercut, bony exostoses, and tori. The ethical standards outlined in the 1964 Declaration of Helsinki were followed for all methodologies that involved human subjects (approval No. PD/1666/1). All participants were fully informed about all the methodologies used in the study, and consent was attained from all participants following their approval.

A suitable stock tray was chosen together with the red thermoplastic compound impression material (Hoffmann Dental Manufaktur GmbH, Berlin, Germany) for the formation of the primary impressions of the upper arch. The primary impressions were then poured with dental plaster for the formation of the primary casts. These primary casts allowed for the subsequent formation of a custom impression tray for each patient using light-cured acrylic resin. 
The trays of the participants were split into 2 groups based on the material used for the final impression. The P-group had border moldings formed of the addition vinyl silicone impression material (Bisico Bielefelder Dentalsilicone GmbH \& Co. KG, Bielefeld, Germany) with the final impressions made with a light-body material cartridge (Aquasil $^{\circledR}$ Ultra Smart Wetting ${ }^{\circledR}$ Impression Material; Dentsply Sirona, York, USA) (Fig. 1A,1B). The Z-group had border moldings formed of the green stick compound impression material (Hoffmann Dental Manufaktur $\mathrm{GmbH}$ ) with a zinc oxide-eugenol material (SS White ${ }^{\circledR}$ Impression Paste; Prima Dental Group, Gloucester, UK) used for the final impressions (Fig. 1C,1D). All materials were used as outlined in the manufacturers' guidelines. The border of the denture base was properly shaped, as it was placed in the mouth and molded in accordance with the lip and cheek muscles for each participant.

A master cast was generated by pouring all impressions with type III dental stone (Elite $\operatorname{Rock}^{\circledR} /$ sandy brown; Zhermack S.p.A., Badia Polesino, Italy). An orthodontic self-curing acrylic resin material (Orthocryl ${ }^{\circledR}$; DENTAURUM GmbH \& Co. KG, Ispringen, Germany) was used for the acrylic denture base of each master cast. Next, a 0.9-gauge, stainless steel U-shaped wire was embedded inside the acrylic denture base material at the palatal rugae area, at the anterior end of the acrylic (Fig. 2). The master cast was then cured for $20 \mathrm{~min}$ in the Ivomat ${ }^{\circledR}$ curing machine (MAJOR MINI 2000; Ivoclar Vivadent S.r.l., Casalecchio di Reno, Italy) containing water heated to $40-46^{\circ} \mathrm{C}$ with the pressure maintained at $30 \mathrm{psi}$, as outlined in the manufacturer's instructions. Two denture bases - one for each border molding and impression group - were formed for each participant. The participants were then seated upright with their head secured onto a head rest prior to the insertion of the denture base into their mouth. The retention force of each denture base was measured in kilograms-force (kgf) using
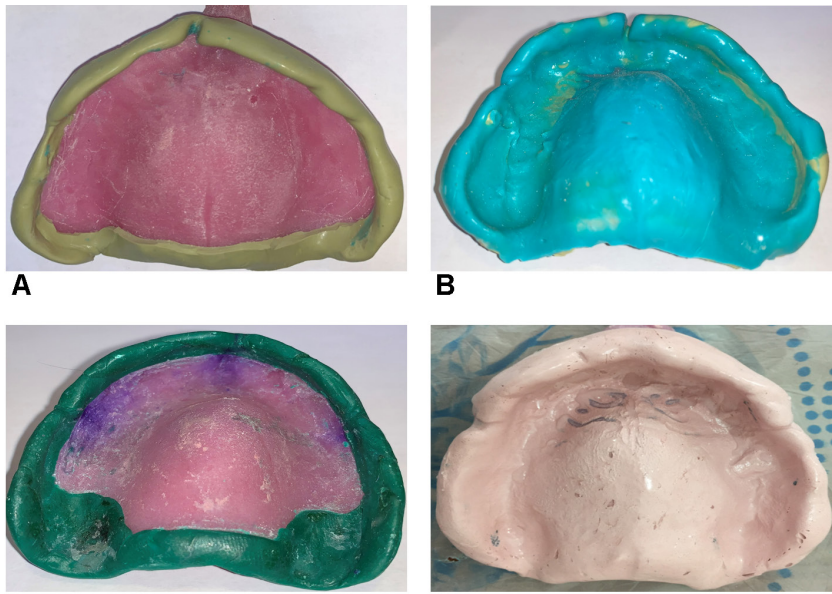

B

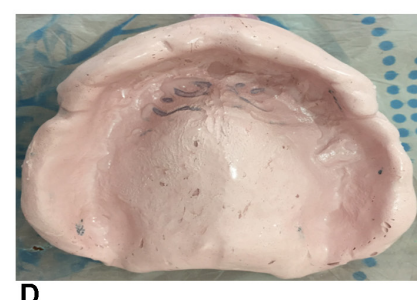

D

Fig. 1. Final impression using the addition vinyl silicone material and a light-body final impression material with the single-step technique $(A, B)$, and using the green stick compound material and zinc oxide-eugenol paste with the sectional technique $(C, D)$

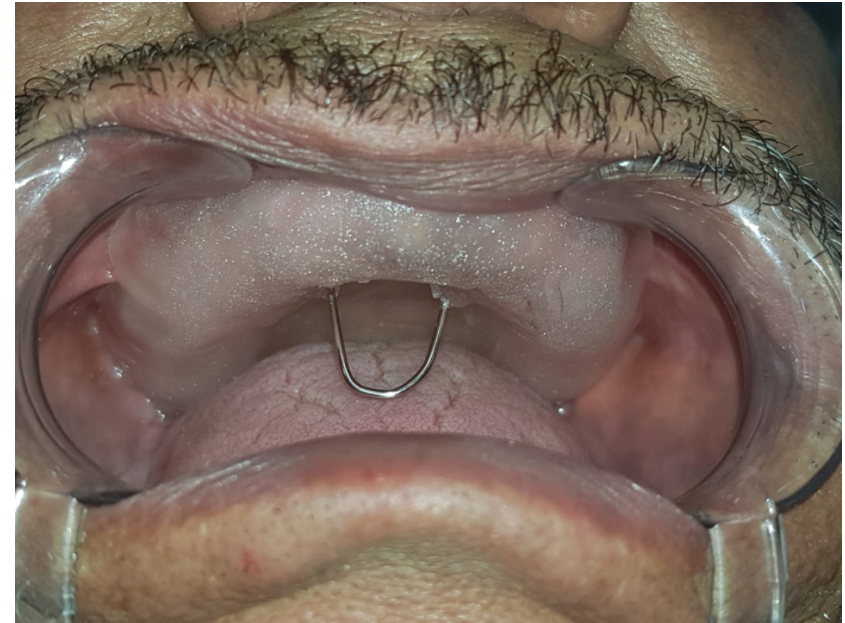

Fig. 2. Stainless steel U-shaped wire embedded inside the self-cured acrylic resin material at the palatal rugae area in the anterior palate

a specifically designed digital force gauge. To link the U-shaped loop in the denture base with the force gauge, a hook was used between them (Fig. 3). Next, downward pulling force was applied to each denture until it was displaced from the mouth (Fig. 4). This step was repeated 4 additional times for a total of 5 runs. To eliminate the bias caused by variations in the technique, all clinical and laboratory procedures were carried out by the same individual.

The IBM SPSS Statistics for Windows software, v. 20 (IBM Corp., Armonk, USA) was used to analyze all the generated data. To assess the degree of normality of the data, the Shapiro-Wilk test was used. This was followed by the analysis of the demographic data (age and gender) for differences using the $X^{2}$ test, with a $p$-value of $<0.05$ indicating statistical significance. Finally, the difference between the mean values obtained for the quantified retention force for each treatment group was analyzed using the Mann-Whitney test, with a $p$-value of $<0.05$ indicating statistical significance.

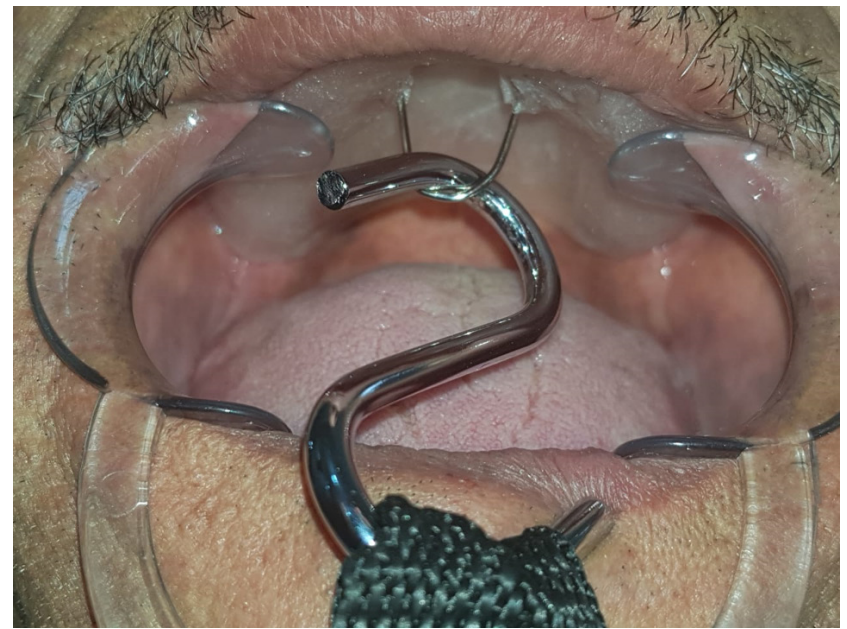

Fig. 3. Digital force gauge used to measure the retention force of the denture base in kilograms-force 


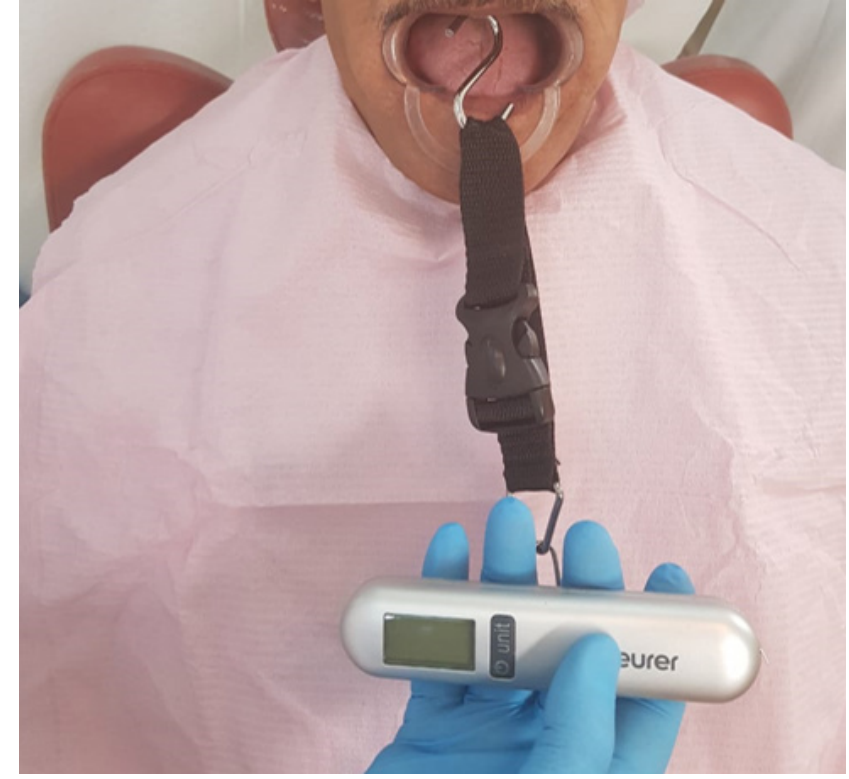

Fig. 4. Pulling force applied downward until the denture was displaced

\section{Results}

This study used a crossover clinical design to quantify the retention force for each participant's denture base when using 2 types of impression materials and 2 different border molding methods. Six men and 4 women $(N=10)$, aged $43-70$ years, took part in the study. The analysis of age and gender indicated no significant differences between the participants for these variables. The mean values (kgf) of the measured retention force with regard to the treatment groups and particular patients are illustrated in Fig. 5. Table 1 lists the mean values (kgf) of the quantified retention force for each treatment group. The data indicates that the retention values for the P-group - with addition vinyl silicon impression border molding material with a light-body final impression - were significantly greater than those for the Z-group, with green stick impression compound material for border molding with a zinc oxide-eugenol final impression.

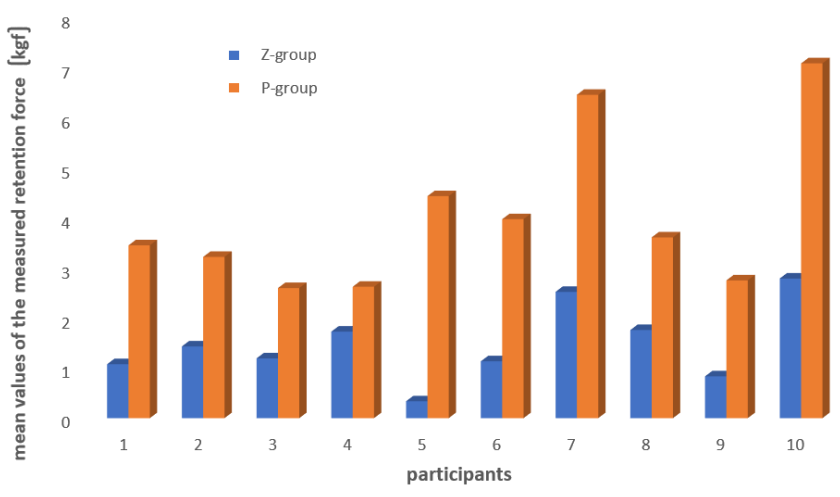

Fig. 5. Mean values of the measured retention force with regard to the treatment groups and particular patients
Table 1. Comparison of the mean values of the measured retention force with regard to the treatment groups

\begin{tabular}{|l|c|c|c|}
\hline \multicolumn{1}{|c|}{ Treatment group } & $N$ & $\begin{array}{c}\text { Retention force } \\
{[\mathrm{kgf}]}\end{array}$ & $p$-value \\
\hline P-group & 10 & $4.02 \pm 1.66$ & $0.000^{*}$ \\
\hline Z-group & 10 & $1.48 \pm 0.90$ & \\
\hline
\end{tabular}

* statistically significant $(p<0.05)$; Mann-Whitney test.

\section{Discussion}

The $\mathrm{CD}$ retention, stability and occlusal vertical dimension are all important, since inadequate retention and stability may significantly affect chewing, and may subsequently increase the patient's complaints. ${ }^{16}$ Despite the fact that CD patients adapt well to their dentures in the mouth after some time of usage, ${ }^{17}$ it is important to obtain a $C D$ with good retention by ensuring the close adaptation of the denture base to the mucosal bearing tissues. ${ }^{18}$

The CD retention may be influenced by various physical factors, including the denture and the mucosa adhesion, saliva cohesion, salivary consistency, and salivary flow. ${ }^{19}$ Furthermore, the type of impression material used and the selected border molding technique both highly impact the retention force of a CD.

Materials frequently used as impression materials are polyethers, polysulfides, hydrocolloids, and addition silicones. Based on the indications of the manufacturer, several of these materials are packaged in cartridges for ease of auto-mixing, which consequently decreases the consumption of time. Moreover, such packaging reduces waste and ensures that the material is free of bubbles when mixed, thereby enhancing the precision of casts. It also decreases the required effort and manipulation time, which is especially beneficial to new students, who may be working with the elderly - as is typically the case when rehabilitating CD patients. ${ }^{9}$ Formerly, zinc oxide-eugenol impression paste, impression plaster and impression compound material were the materials most commonly used. They were not only challenging with respect to manipulation, but they would usually alter or fracture if withdrawn from a deep undercut. ${ }^{20}$ Considering that the age of the participants in this study was between 43 and 70 years, then based on the findings, there should be a review of the daily clinical use of zinc oxide as a final impression material, following the green stick compound for the formation of CD impressions. The findings indicate that there is a significant advantage of changing to the new technique using addition vinyl silicon for border molding, followed by a light-body material for final impressions employing the single-step technique. This would help to alleviate the patient's burden and reduce the time spent in the clinic.

Another noteworthy point is the impact of gender on the $\mathrm{CD}$ retention, as women are reported to show greater degrees of resorption than men. ${ }^{21}$ In the case of women, 
the growth and development of osteoclasts take more time as a result of a deficiency in estrogen levels; this, in turn, leads to increased bone resorption, which places female patients at a higher risk of more extensive ridge resorption. ${ }^{22}$ The finding of this study, however, was not statistically significant with respect to the difference between genders, although only 4 women were included in the study. Our results are further supported by research conducted by Khuder et al., who determined that no association existed between advanced bone resorption and the patients' age and gender. ${ }^{23}$

In the present study, the mean retention force for the denture base material on insertion was decreased when the green stick for border molding and a zinc oxide material for the final impression were used. The observed mean retention values were significantly greater when the addition vinyl silicon border molding material and a light-body final impression material were employed. The findings of this study are supported by the research of Pachar et al., where the green stick compound with light-body final impressions yielded the lowest mean CD retention value. ${ }^{19}$ That said, in that study, the mean retention value for green stick border molding was greater than the value attained in this study, with $4.59 \mathrm{kgf}$ in the former compared to $1.48 \mathrm{kgf}$ in the latter. This discrepancy can be explained by the variation in the final impression material used in the 2 studies; Pachar et al. ${ }^{19}$ used light-body addition silicone and this study used a zinc-oxide impression material. These findings are also supported by a study performed by Gupta et al.,24 who reported retention values for the green stick material of $1.50 \mathrm{kgf}$, which is in keeping with the results of this study (1.48 kgf). In contrast, their result attained for light-body polyvinyl siloxane used as an impression material was lower (1.95 kgf) than that attained in this study (4.02 kgf). This discrepancy, however, could be attributed to the use of different border molding materials, with heavy-body addition silicone (putty) used in Gupta et al's study ${ }^{24}$ and addition vinyl silicone used in this study.

Another study, conducted by Tasleem et al., reported contrasting findings, where 2 groups of edentulous patients were only found to differ in the time taken to complete the impression technique; no significant differences were noted with respect to the border molding material employed. ${ }^{25}$ However, the clinical significance of the findings of Tasleem et al. is questionable, as although their study was a cross-sectional study, it was based on a questionnaire and the assessment of the retention force was dependent on the patients' perspective. ${ }^{25}$

The findings of the present study also contradict those of Qanungo et al., who determined that the sectional technique was more retentive than the single-step border molding technique. ${ }^{26}$ Again, this discrepancy may be attributed to the nature of the impression material used. In their study, irreversible hydrocolloid was used as the primary impression material, whereas in the present study, an impression compound was used as the primary impression material.
Finally, only 1 form of polyvinyl siloxane impression material was assessed in this study, even though various different forms are available on the market. This is due to a high cost of polyvinyl siloxane materials. This study did not evaluate the time involved in completing the impression procedure. Furthermore, the study did not consider the retention force of the denture base for the lower arch. Our study concentrated solely on assessing the denture base retention force for the upper arch, so further research is proposed for assessing these other factors.

\section{Conclusions}

After taking into account the limitations of this study, it was concluded that the use of the addition vinyl silicone material together with a light-body final impression material and the single-step technique resulted in superior retention in the acrylic denture base over the denture base formed with the use of the green stick and zinc-oxide eugenol as the final impression material using the sectional technique.

\section{ORCID iDs}

Tameem Khuder Jassim (1) https://orcid.org/0000-0002-7630-599X Ali Ehsan Kareem (1) https://orcid.org/0000-0001-9897-0053 Mohamed Adnan Alloaibi (1) https://orcid.org/0000-0002-3646-9914

\section{References}

1. Allen PF, McMillan AS. A longitudinal study of quality of life outcomes in older adults requesting implant prostheses and complete removable dentures. Clin Oral Implants Res. 2003;14(2):173-179.

2. Gotfredsen K, Walls AWG. What dentition assures oral function? Clin Oral Implants Res. 2007;18(Suppl 3):34-45.

3. Papadiochou S, Emmanouil I, Papadiochos I. Denture adhesives: A systematic review. J Prosthet Dent. 2015;113(5):391-397.e2.

4. Rao S, Chowdhary R, Mahoorkar S. A systematic review of impression technique for conventional complete denture. J Indian Prosthodont Soc. 2010;10(2):105-111.

5. Petrie CS, Walker MP, Williams K. A survey of U.S. prosthodontists and dental schools on the current materials and methods for final impressions for complete denture prosthodontics. J Prosthodont. 2005;14(4):253-262.

6. Boucher $\mathrm{CO}$. Complete denture impressions based upon the anatomy of the mouth. J Am Dent Assoc. 1944;31(17):1174-1181.

7. Davis DM. Developing an analogue/substitute for the maxillary denture-bearing area. In: Zarb GA, Bolender CL, Eckert SE, et al., eds. Prosthodontic Treatment for Edentulous Patients: Complete Dentures and Implant-Supported Prostheses. $12^{\text {th }}$ ed. St. Louis, USA: Mosby; 2004:211-231.

8. The glossary of prosthodontic terms: Ninth edition. J Prosthet Dent. 2017;117(5S):e1-e105.

9. Woelfel JB, Hickey JC, Berg T Jr. Contour variations in one patient's impressions made by seven dentists. J Am Dent Assoc. 1963;67:1-9.

10. Smith DE, Toolson LB, Bolender CL, Lord JL. One-step border molding of complete denture impressions using a polyether impression material. J Prosthet Dent. 1979;41(3):347-351.

11. Friedman S. Edentulous impression procedures for maximum retention and stability. J Prosthet Dent. 1957;7(1):14-26.

12. Chaffee NR, Cooper LF, Felton DA. A technique for border molding edentulous impressions using vinyl polysiloxane material. $J$ Prosthodont. 1999;8(2):129-134. 
13. Solomon EGR. Single stage silicone border molded closed mouth impression technique - part II. J Indian Prosthodont Soc. 2011;11(3):183.

14. Ye Y, Sun J. Simplified complete denture: A systematic review of the literature. J Prosthodont. 2017;26(4):267-274.

15. Marxkors R. Die Funktionsabformung. Dtsch Zahnarztl $Z$. 1970;25:58-63.

16. Medeiros Ribeiro JA, Bastos Machado de Resende CM, Correia Lopes AL, Mestriner W Jr, Roncalli AG, Farias-Neto A, da Fonte Porto Carreiro A. Evaluation of complete denture quality and masticatory efficiency in denture wearers. Int J Prosthodont. 2012;25(6):625-630.

17. Raftu G, Sin EC, Leon A, Caraiane A, Buștiuc SG. The clinical and statistical study on the quality of complete acrlylic dentures. Rom J Oral Rehabil. 2019;11(1):116-120.

18. Giglio JJ, Lace WP, Arden $\mathrm{H}$. Factors affecting retention and stability of complete dentures. J Prosthet Dent. 1962;12(5):848-856.

19. Pachar RB, Singla Y, Kumar P. Evaluation and comparison of the effect of different border molding materials on complete denture retention: An in vivo study. J Contemp Dent Pract. 2018;19(8):982-987.

20. Anusavice KJ, Shen C, Rawls HR, eds. Phillips' Science of Dental Materials. $11^{\text {th }}$ ed. St. Louis, USA: Saunders; 2003:177-178.

21. Jayaram B, Shenoy KK. Analysis of mandibular ridge resorption in completely edentulous patients using digital panoramic radiography. J Dent Med Sci. 2017;16:66-73.

22. Nishimura I, Hosokawa R, Kaplan ML, Atwood DA. Animal model for evaluating the effect of systemic estrogen deficiency on residual ridge resorption. J Prosthet Dent. 1995;73(3):304-310.

23. Khuder T, Yunus N, Sulaiman E, Ibrahim N, Khalid T, Masood M. Association between occlusal force distribution in implant overdenture prostheses and residual ridge resorption. J Oral Rehabil. 2017;44(5):398-404.

24. Gupta R, Luthra RP, Mehta S. Comparative analysis of two border molding techniques and materials on maxillary complete denture retention - an in-vivo study. J Adv Med Dent Scie Res. 2015;3(4):109-112.

25. Tasleem R, Bin Saeed MH, Javed MU. Comparison of complete denture fabricated by two different border molding materials, in terms of patients'satisfaction. J Ayub Med Coll Abbottabad. 2013;25(3-4):78-80.

26. Qanungo A, Aras MA, Chitre V, Coutinho I, Rajagopal P, Mysore A. Comparative evaluation of border molding using two different techniques in maxillary edentulous arches: A clinical study. J Indian Prosthodont Soc. 2016;16(4):340-345. 